Available online on 15.03.2017 at http://iddtonline.info
(C) 2011-17, publisher and licensee JDDT, This is an Open Access article which permits unrestricted
noncommercial use, provided the original work is properly cited

Research Article

\title{
FORMULATION AND EVALUATION OF BILAYER TABLETS OF PROPRANOLOL HYDROCHLORIDE
}

\author{
Momin Shahanoor ${ }^{* 1}$, Khan Shadab ${ }^{2}$, Ghadage D.M. ${ }^{1}$, Yadav A.V. ${ }^{1}$, Wagh Amit ${ }^{1}$ \\ ${ }^{1}$ Department of Pharmaceutics, Gourishankar Institute of Pharmaceutical Education and Research Limb, Satara, Maharashtra, India \\ ${ }^{2}$ Department of Pharmaceutics, M.C.E. Society's Allana College of Pharmacy, Pune-411001, Maharashtra, India
}

\section{ABSTRACT}

The purpose of this study is to prepare a bilayer tablet of Propranolol $\mathrm{HCl}$ using Wet granulation technology and to formulate optimized formulation. Propranolol $\mathrm{HCl}$, a nonselective $\beta$-adrenergic blocker which is the best drug candidate to formulate in to bilayer tablets fast release of drug from immediate release layer can give rapid onset of action which will help which will help to reduce Blood pressure within short period of time while maintenance dose of Propranolol $\mathrm{HCl}$ will maintain plasma concentration within therapeutic range for $12 \mathrm{hrs}$ having short half-life (3-5 hr) and first pass metabolism favors for sustained release dosage form. The tablets were prepared by wet granulation method. Hydrophobic matrix materials such as ethyl cellulose were used, which can release the drug up to $12 \mathrm{hrs}$ in predetermined rate. Binder used was Starch paste (10\%). The influence of hydrophobic polymer and granulation technique was studied. In this study, a bilayer tablet was prepared which contains an immediate release portion layer and sustained release portion. Ethyl cellulose were used as in alone, for Sustained release and Superdisintegrant Cross Povidone for immediate release used. The bilayer tablets were characterized by Calibration Curve, Calculation of Dose, Bulk Density, Tapped density, Angle of repose, Carr's Index, Hausner's ratio, Weight Variation, Hardness, Friability, Thickness, Drug Content and Invitro dissolution profile. The granules showed satisfactory flow properties and compressibility. Best Formulation F3 [Drug + Ethylcellulose (1:3)] showed High \% drug release $87.40 \%$ release, high drug content, high hardness and friability. Hence, it was found better than F1 and F2 so F3 is the best formulation.

Keywords: Propranolol Hydrochloride, Ethylcellulose, Bilayer Tablets.

\section{Article Info}

Received 12 Feb 2017; Review Completed 01 March 2017; Accepted 01 March 2017, Available online 15 March 2017

Cite this article as:

Momin S, Khan S, Ghadage DM, Yadav AV, Wagh A, Formulation and evaluation of bilayer tablets of propranolol hydrochloride, Journal of Drug Delivery and Therapeutics. 2017; 7(2)50-57. DOI: http://dx.doi.org/10.22270/jddt.v7i2.1399

*Address for Correspondence

Momin Shahanoor, Department of Pharmaceutics, Gourishankar Institute of Pharmaceutical Education and Research Limb, Satara, Maharashtra, India. Email: shahanoormomin@gmail.com

\section{INTRODUCTION:}

Oral route is one of the most popular routes of drug delivery due to its ease of administration, patient compliance, least sterility constraints and flexible design of Dosage form. The oral route of administration is the most preferred route due to its many advantages like ease of administration, accurate dosage, self-medication, pain avoidance, versatility and patient compliance. Tablets and capsules are the most popular dosage forms. Ideally a drug to provide desired therapeutic action should arrive rapidly at the site of action in optimum concentration, remain there for the desire time, be excluded from other site. The fact that absorption rate of drug into the body can be decreased by reduction of the rate of release of the drug from the dosage form is one of the most recent and interesting result of pharmaceutical research. But one important drawback of such dosage forms is Dysphasia or difficulty in swallowing ${ }^{1-2}$. This is seen to afflict nearly $35 \%$ of the general population. This disorder is also associated with a number of pathological 
conditions including stroke, Parkinson's disease, neurological disorders, AIDS etc.

Dual release Tablets is a unit compressed Tablets dosage form intended for oral Application. It contains two layers in which one layer having conventional or immediate release part of single or multiple actives; another layer is sustained or controlled release part of single or multiple actives. They are also called as Bilayer Tablets, multi-layer Matrix Tablets.. A bilayer Tablets is a type of multiple compressed Tablets. Tablets are composed of two layers of granulation compressed together. Monograms and other distinctive marking may be compressed in the surface of the bilayer Tablets. Coloring the separate layer provide many possibilities for unique Tablets identity. There are some applications like Bilayer Tablets are mainly used in the combination therapy. Bilayer Tablets are used to deliver the loading dose and sustained dose of the same or different drugs. Bilayer Tablets are used to deliver the two different drugs having different release. They are used as an extension of a conventional technology Potential use of single entity feed granules. Patient compliance is enhanced leading to improved drug regimen efficacy. Patient convenience is improved because fewer daily doses are required compared to traditional drug delivery system. Maintain physical and chemical stability. Retain potency and ensure dose accuracy ${ }^{3-4}$.

\subsection{Advantages of Bilayer Tablets over Conventional Tablets:}

Blood level of a drug can be held at consistent therapeutic levels for improved drug delivery, accuracy, safety and reduced side effects. Reduction of adverse effects can be accomplished by targeting the drug release to the absorption site as well as controlling the rate of release, enabling the total drug content to be reduced. Patient convenience is improved because fewer daily doses are required compared to traditional delivery systems. Patient compliance is enhanced leading to improved drug regimen efficacy. Bilayer Tablets readily lend themselves to repeat action products, where in one layer on layered Tablets provides the initial dose, rapidly disintegrate in the stomach. The other layers are insoluble in gastric media but are released in the intestinal environment. In bilayer Tablets, where in one layer on layered Tablets provides as immediate Release and other layer acts as sustained release. In sustained release drug delivery system, several approaches are available to add the loading dose to the maintenance dose such as simple addition of a sustained dose of drug to the sustained portion and placement of initial dose in a Tablets coat with the sustaining portion in the core as in compression coated Tablets. An alternative approach for having the loading dose and maintenance dose in a Tablets is the formulation of drug in a multi layered Tablets or bilayer Tablets system. This bilayer approach is a convenient method. Hence it makes possible to formulate sustained release preparations with the immediate release quantity in one layer and the slow release portion will disintegrate rapidly after ingestion thus providing the Initial dose of medication for immediate onset of action, where as the another layer in the matrix layer remain intact during most of the time of its passage through the intestine, While dissolving slowly (sustained manner) from its exposed faces in this passage, which helps to maintain the blood level initially reached $^{5}$.

\subsection{Ideal Characteristics of Bilayer Tablets ${ }^{6}$ :-}

1) A bi-layer tablet should have elegant product identity while free of defects like chips, cracks, discoloration and contamination.

2) It should have sufficient strength to with stand mechanical shock during its production packaging, shipping and dispensing.

3) It should have the chemical and physical stability to maintain its physical attributes over time. The bilayer Tablets must be able to release the medicinal agents in a predictable and reproducible manner.

4) It must have a chemical stability shelf-life, so as not to follow alteration of the medicinal agents.

\subsection{Challenges in Bilayer Tablet Manufacturing ${ }^{7}$ :}

Conceptually, bilayer Tablets can be seen as two singlelayer Tablets compressed into one. In Practice, there are some manufacturing challenges.

\subsubsection{Delamination:}

Tablets fall apart when the two halves of the Tablets do not bond completely. The two granulations should adhere when compressed.

\subsubsection{Cross-contamination:}

When the granulation of the first layer intermingles with the granulation of the second layer or vice versa, crosscontamination occurs. It may conquer the very purpose of the bilayer Tablets. Proper dust collection goes a long way toward preventing cross contamination.

\subsubsection{Production yields:}

To prevent cross contamination, dust collection is required which leads to losses. Thus, bilayer Tablets have lower yields than single-layer Tablets.

\subsubsection{Cost:}

Bilayer tableting is more expensive than single layer tableting for several reasons. First, the Tablets press costs more. Second, the press generally runs more slowly in bilayer mode. Third, development of two compatible granulations is must, which means more time spent on formulation development, analysis and validation. These factors, if not well controlled/optimized, in one way or another will impact the bilayer compression per se and the quality attributes of the bilayer Tablets (sufficient mechanical strength to maintain its integrity and individual layer weight control). Therefore, it is critical to obtain an insight into the root causes to enable design of a robust product and process.

\subsection{Types of bilayer Tablets press:}

\subsubsection{Single sided press:}

The simplest design is a single sided press with both chambers of the doublet feeder separated from each 
other. Each chamber is gravity or forced fed with different power, producing the two individual layers of Tablets. When die passes under the feeder, it is first loaded with the first layer powder followed by the second layer powder. Then the entire Tablets is compressed in one or two steps.

\section{Limitations of the single sided press:}

1) No weight monitoring / control of the individual layers.

2) No distinct visual separation between the two layers.

3) Very short first layer dwell time due to the small compression roller, possibly resulting in poor deaceration, capping and hardness problems.

4) This may be corrected by reducing the turret rotation speed (to extend the dwell time) but with the consequence of lower Tablets output.

\subsubsection{Double sided Tablets press:}

In most double sided Tablets presses with automated production control use compression force to monitor and control Tablets weight. The effective peak compression force exerted on each individual Tablets or layer is measured by the control system at main compression of the layer. This measured peak compression force is the signal used by the control system to reject out of tolerance and correct the die fill depth when required.

\subsubsection{Bilayer Tablets press with displacement monitoring:}

The displacement Tablets weight control principle is fundamentally different from the principle based upon compression force. When measuring displacement, the control system sensitivity does not depend on the Tablets weight but depends on the applied precompression force.

\subsection{Preparation of Bilayer Tablets: $:^{9-11}$}

Bilayer Tablets are prepared with one layer of drug for immediate release with the second layer designed to release drug later, either as a second dose or in an extended release. The bilayer Tablets with two incompatible drugs can also be prepared by compressing separate layers of each drug so as to minimize area of contact between two layers. An additional intermediate layer of inert material may also be included. To produce adequate Tablets formulation, certain requirements such as sufficient mechanical strength and desired drug release profile must be met. At times, this may be difficult task for formulator to achieve these conditions especially in bilayer Tablets formulation where double compression technique is involved, because of poor flow and compatibility characteristic of the drug which will result in capping and/or lamination. The compaction of a material involves both the compressibility and consolidation.

\section{Compression:}

It is defined as reduction in bulk volume by eliminating voids and bringing particles into closer contacts.

\section{Consolidation:}

It is the property of the material in which there is increased mechanical strength due to interparticulate interaction (bonding). The compression force on layer 1 was found to be major factor influencing Tablets delamination.

\section{MATERIAL AND METHOD:}

\section{Materials:}

Propranolol Hydrochloride was obtained as a gift sample from Renuka Raw Pharma (Mumbai), India. All over chemicals were purchased from Merck Research Lab., Fine Chem Industries, Mumbai, India.

\section{Methods:}

\subsection{Preformulation Studies:}

The drug substance of Propranolol $\mathrm{HCl}$ was characterized for their identity and purity. The following studies were performed ${ }^{12}$ :

\subsection{Determination of Absorption Maxima of Propranolol HCl:}

A solution of Propranolol $\mathrm{HCl}$ containing the concentration $10 \mu \mathrm{g} / \mathrm{ml}$ was prepared in $0.1 \mathrm{~N} \mathrm{HCl}$, \& phosphate buffer $6.8 \mathrm{P}^{\mathrm{H}}$ respectively, UV spectrum was taken using Double beam UV/VIS spectrophotometer. The solution was scanned in the range of $200-400 \mathrm{~nm}$.

\subsection{Preparation Calibration Curve for Propranolol HCl:}

$10 \mathrm{mg}$ of Propranolol $\mathrm{HCl}$ drug was accurately weighed and dissolved in $10 \mathrm{ml}$ of $0.1 \mathrm{~N} \mathrm{HCl}$ and $6.8 \mathrm{pH}$ in $10 \mathrm{ml}$ volumetric flask to make $(1000 \mu \mathrm{g} / \mathrm{ml})$ standard stock solution(1). Then $1 \mathrm{ml}$ stock solution (1) was taken in another $10 \mathrm{ml}$ volumetric flask to make $(100 \mu \mathrm{g} / \mathrm{ml})$ standard stock solution(2), then again $1 \mathrm{ml}$ of stock solution (2) was taken in another $10 \mathrm{ml}$ volumetric flask and then final concentrations were prepared $2,4,6,8$, and $10 \mu \mathrm{g} / \mathrm{ml}$ with $0.1 \mathrm{~N} \mathrm{HCL}$, and $6.8 \mathrm{pH}$. The absorbance of standard solution was determined using UV/ VIS spectrophotometer at $290 \mathrm{~nm}$. Linearity of standard curve was assessed from the square of correlation coefficient $\left(r^{2}\right)$ which is determined by leastsquare linear regression analysis.

\subsection{Drug and Excipient Compatibility Studies:}

Compatibility of the Propranolol Hydrochloride with Ethylcellulose used to formulate bilayer tablets was established by FTIR spectral analysis. FTIR spectral analysis of Propranolol Hydrochloride, individual excipient and combination of Propranolol Hydrochloride and Ethylcellulose was carried out to investigate the changes in chemical composition of the drug after combining it with the excipients. Compatibility study was carried out on Fourier Transform Infrared Spectrometer $^{13}$.

\subsection{Calculation of Dose:-}

The Loading dose and maintenance dose of Propranolol Bilayer tablets was calculated by following equation using available pharmacokinetic data. 


$$
\text { Dt }=\text { Dose }\left(1+0.693 \times \mathbf{t} / t_{1 / 2}\right)
$$

Where, Dt $=$ Total dose of drug; Dose $=$ dose of immediate release part $(25 \mathrm{mg}) ; \mathrm{t}=$ time (hours) $\mathrm{t}_{1 / 2}=$ half-life of drug (3.79)

Dt $=25(1+0.693 \times 12 / 3.79)=80 \mathrm{mg}$ hence formulation should contain total dose $80 \mathrm{mg}$ with $25 \mathrm{mg}$ loading dose i.e. dose of immediate release and $55 \mathrm{mg}$ is maintenance dose i.e dose of sustained release.

\subsection{Manufacturing Process ${ }^{14-18}$ :}

The bilayer Tablets of propranolol hydrochloride were prepared by the wet granulation method. The drug and polymers for both fast release and sustaining layer were passed through a $22-\mu \mathrm{m}$ sieve before their use in the formulation.

\subsubsection{Steps Involved in Formulation of Propranolol HCl Bilayer Tablets:}

Starch paste $(10 \% \mathrm{~m} / \mathrm{m})$ as binder is used as granulating agent and granules are prepared. The (Sustained release layer) Propranolol hydrochloride, Ethyl cellulose, Magnesium stearate, Talc are passed through sieve No.60 and then Starch Paste added little by little so that a coherent mass formed when crumps on slight application of pressure then coherent mass passed through sieve No. 10. The granules dried at $60^{\circ} \mathrm{C}$ for 30 minutes. All dried granules passed through sieve No. 22 below which Sieve No. 44 was kept. The granules retained on sieve No. 44 were desired and the powder which passed through sieve No. 44 was fine granules.

Table 1: Composition of Sustained Release Propranolol HCl Tablets

\begin{tabular}{|c|c|c|c|}
\hline Ingredients (mg) & F1(1:1) & F2 (1:2) & F3 (1:3) \\
\hline Propranolol HCl & 55 & 55 & 55 \\
\hline Ethyl Cellulose & 55 & 110 & 165 \\
\hline Lactose & 130 & 75 & 20 \\
\hline Starch Paste & 25 & 25 & 25 \\
\hline Magnesium Stearate & 3 & 3 & 3 \\
\hline Talc & 2 & 2 & 2 \\
\hline Avg. Weight of SR Layer Tablet & 270 & 270 & 270 \\
\hline
\end{tabular}

\subsubsection{Preparation of Immediate Release Propranolol HCI Tablet by Wet Granulation Method:}

Starch paste $(10 \% \mathrm{~m} / \mathrm{m})$ as binder is used as granulating agent and granules are prepared. The (Immediate release layer) Propranolol hydrochloride, Cross Povidone, Magnesium stearate, Talc are passed through sieve No.60 and then Starch Paste added little by little so that a coherent mass formed when crumps on slight application of pressure then coherent mass passed through sieve No. 10. The granules dried at $60^{\circ} \mathrm{C}$ for 30 minutes. All dried granules passed through sieve No. 22 below which Sieve No. 44 was kept. The granules retained on sieve No. 44 were desired and the powder which passed through sieve No. 44 was fine granules.

Table 2: Composition of Immediate Propranolol HCI Release Tablets

\begin{tabular}{|c|c|c|}
\hline Sr. No. & Ingredients (mg) & IR \\
\hline 1 & Propranolol HCl & 25 \\
\hline 2 & Cross Povidone & 1 \\
\hline 3 & Starch Paste (10\%) & 3 \\
\hline 4 & Magnesium Stearate & 0.5 \\
\hline 5 & Talc & 0.5 \\
\hline & Avg. Weight of IR Layer Tablet & 30 \\
\hline
\end{tabular}

Table 3: Total Weight of Propranolol HCl Bi-layer Tablets

\begin{tabular}{|c|c|c|c|}
\hline $\begin{array}{c}\text { Total Weight of Bi-layer } \\
\text { Tablets (mg) }\end{array}$ & F1 (1:1) & F2 (1:2) & F3 (1:3) \\
\cline { 2 - 4 } & 300 & 300 & 300 \\
\hline
\end{tabular}

\subsection{Evaluation of Propranolol HCI Bilayer Tablets:}

\subsubsection{Precompression Studies:}

The flow properties of immediate release blend and floating sustained release granules (before compression) were characterized in terms of loose bulk density,
Tapped bulk density, Angle of repose, Carr's index \& Hausner's ratio.

\section{a) Loose Bulk Density:}

It is indicative of the packing of particles and as such is greatly influenced by the size of granules. Loose bulk 
density of Tablets was determined by pouring gently $2 \mathrm{~g}$ of the powder blend from each formula through a glass funnel into $10 \mathrm{ml}$ measuring cylinder. The volumes occupied by the samples were noted. Loose bulk density was expressed in $(\mathrm{g} / \mathrm{ml})$ and calculated by using following formula.

Bulk Density $=($ Weight of the Granule / Bulk volume $)$

\section{b) Tapped Bulk Density:}

It was determined by pouring gently $2 \mathrm{~g}$ of the powder blend from each formula through a glass funnel into 10 $\mathrm{ml}$ measuring cylinder. The cylinder was tapped gently on to a hard surface from the height of 2 inches at second interval until a constant volume was obtained. Volume occupied by the sample after tapping was noted. Tapped density was expressed in $(\mathrm{g} / \mathrm{ml})$ and calculated by using following formula.

Tapped Density $=($ Weight of the Granule $/$ Tapped volume $)$

\section{c) Angle of Repose}

Angle of repose is defined as the maximum angle possible between the surface of the pile of the Granule and the horizontal plane. Angle of repose of different formulations was measured according to fixed height funnel standing method.

$$
\begin{aligned}
& \left.\qquad \tan \boldsymbol{\theta}=\mathbf{h} / \mathbf{r} ; \quad \boldsymbol{\theta}=\tan ^{-\mathbf{1}} \mathbf{h} / \mathbf{r}\right) \\
& \text { d) Carr's Index } \\
& \text { Compressibility index }(\mathrm{CI}) \text { or Carr's index value of } \\
& \text { microparticles was computed according to the equation: } \\
& \text { Carr }(\%)=[(\text { Tapped density }- \text { Bulk Density }) / \text { Tapped } \\
& \text { Density }] \times 100
\end{aligned}
$$

\section{e) Hausner's Ratio:}

Hausner's ratio of micro particles was determined by comparing the tapped density to the bulk density using the equation:

\subsubsection{Postcompression Studies:}

\section{a) Weight Variation:}

It was performed as per the method given in the Indian Pharmacopoeia (1996). 20 Tablets were selected randomly from the formulation and the average weight was determined. Then individual Tablets were weighed and the individual weight was compared with the average weight. Following are the formulas:

$$
\begin{gathered}
\% \text { Deviation }=(\text { Average Weight }- \text { Individual Weight }) / \\
\text { Average Weight. } \times 100
\end{gathered}
$$

\section{b) Hardness:}

This test is used to check the hardness of a tablet which may undergo chipping or breakage during storage, transportation and handling. In this five Tablets were selected at random and the hardness of each Tablets formulation and marketed Tablets was measured with Monsanto hardness tester. The hardness is usually measured in terms of $\mathrm{kg} / \mathrm{cm}^{2}$.

c) Friability:
The friability test was carried out to evaluate the hardness and stability instantly. The Tablets friability was measured according to the Indian Pharmacopoeia. In this, 10 Tablets were weighed initially and put in a rotating apparatus drum (Roche friabilator). Then, they are subjected to fall from 6 inches height. After completion of 100 rotations, loose dust particles were removed from the Tablets after the test and the Tablets were again weighed. The Tablets friability was expressed in (\%). The percentage friability of the Tablets formulation was calculated by using following formula is given below:

$\%$ Friability $=$ Initial Wt of Tablets - Final Wt of Tablets $\mathrm{x} 100$

Initial Wt of Tablets

\section{d) Tablets Thickness and Size:}

Thickness and size of Tablets were important for uniformity of Tablets size. Thickness and size of the Tablets formulation was measured using Vernier caliper and is expressed as ( $\mathrm{mm})$.

\section{e) Drug Content Uniformity:}

Ten Tablets were finely powdered and an amount equivalent to $40 \mathrm{mg}$ of propranolol hydrochloride was accurately weighed and transferred to a $100 \mathrm{ml}$ volumetric flask. Then $70 \mathrm{ml}$ methanol was added. The flask was shaken for 10 minutes. Finally, the volume was made up to the mark with methanol. The mixture was then filtered and $1 \mathrm{ml}$ of the filtrate was suitably diluted with methanol to obtain a solution containing about $40 \mu \mathrm{g} \mathrm{ml}{ }^{-1}$ of propranolol hydrochloride and analyzed for Propranolol hydrochloride content at 290 $\mathrm{nm}$ using a double beam UV/Visible and methanol as a blank.

\section{f) In-vitro Drug Release Study of Propranolol HCl Bilayer Tablets:}

Release of Propranolol Hydrochloride was determined using a USP, six stage dissolution rate test apparatus- I at 50rpm. The dissolution was studied using $900 \mathrm{~mL}$ of simulated gastric fluid $0.1 \mathrm{~N} \mathrm{HCl}$ (without enzyme, $\mathrm{pH}$ 1.2) for the first $2 \mathrm{hrs}$ and followed by a simulated intestinal fluid (without enzyme $\mathrm{pH}$ 6.8) for remaining 10 hours. The temperature was maintained at $37 \pm 0.5^{\circ} \mathrm{C}$. The sample $(5 \mathrm{ml})$ was withdrawn at different time intervals i.e. $1,2,3,4,5,6,7,8,9,10,11,12 \mathrm{hrs}$ filter through whatman filter paper and replaced by an equal volume of dissolution medium sample were suitably diluted and analyzed for Propranolol hydrochloride content at $290 \mathrm{~nm}$.

\section{RESULTS AND DISCUSSION:}

\subsection{Determination of Absorption Maxima of Propranolol HCl:}

The absorbance maximum of Propranolol $\mathrm{HCl}$ was found to be at $290 \mathrm{~nm}$.

\subsection{Drug and Excipient Compatibility Studies:}

No significant changes were observed in the IR spectra as shown in Figure No. 2. 


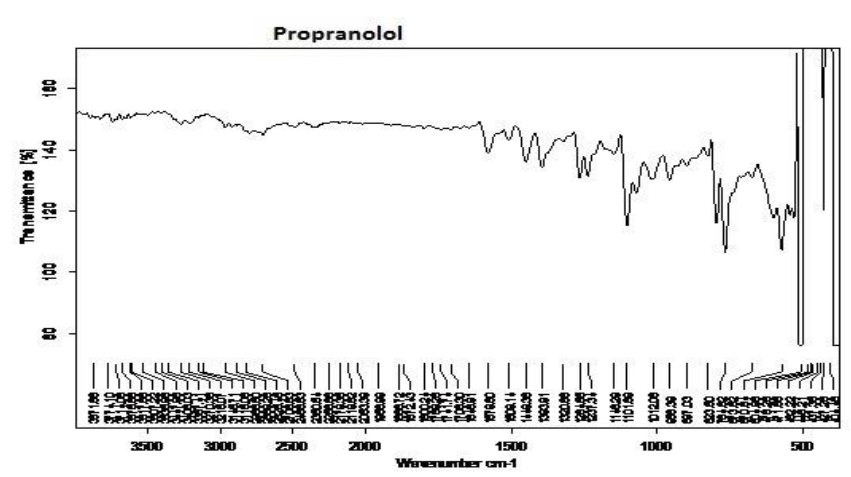

Figure 1: FTIR Spectra of Propranolol HCl

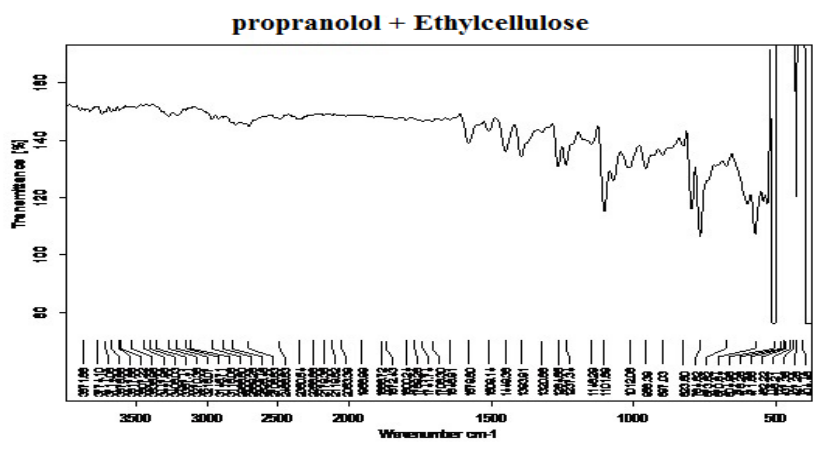

Figure 2: FTIR Spectra of Propranolol HCl with Ethylcellulose

3.3 Pre Compression Parameters for Immediate Release Powder Blend:

The immediate release powder blend shows good flowing property.

Table 4: Flow Property of Immediate Release Powder Blend

\begin{tabular}{|c|c|c|}
\hline Sr. No & Parameters & IR Formulation \\
\hline 1 & Bulk Density & 0.551 \\
\hline 2 & Tapped Density & 0.760 \\
\hline 3 & \% Carr's Index & 27.52 \\
\hline 4 & Hausner's Ratio & 1.13 \\
\hline 5 & Angle of repose & $24.89^{\circ}$ \\
\hline
\end{tabular}

\subsection{Precompression Parameters of Sustained Release Granules of Propranolol HCl:}

The results for precompression parameters of sustained release granules of Propranolol $\mathrm{HCl}$ are shown in Table $\mathbf{5}$.

Table 5: Precompression Parameters of Sustained Release Granules Propranolol HCl

\begin{tabular}{|c|c|c|c|c|}
\hline Sr. No & Parameters & F1 & F2 & F3 \\
\hline $\mathbf{1}$ & Bulk Density $(\mathrm{gm} / \mathrm{ml})$ & 0.6060 & 0.5882 & 0.5714 \\
\hline $\mathbf{2}$ & Tapped Density & 0.6451 & 0.6250 & 0.6060 \\
\hline $\mathbf{3}$ & \% Carr's Index (\%) & 6.06 & 5.88 & 5.71 \\
\hline $\mathbf{4}$ & Hausner's Ratio & 1.064 & 1.062 & 1.060 \\
\hline $\mathbf{5}$ & Angle of repose & $19.02^{0}$ & $22.61^{0}$ & $25.46^{0}$ \\
\hline
\end{tabular}

All the batches pass the Pharmacopoeial limits.

3.5 Post Compression Parameters for Sustained Release Propranolol HCl Bilayer Tablets:

The results for postcompression parameters of sustained release Propranolol HCl bilayer tablets are shown in Table 6.

Table 6: Postcompression Parameters of Sustained Release Propranolol HCl Bilayer Tablet

\begin{tabular}{|c|c|c|c|c|}
\hline Sr. No & Parameters & F1 & F2 & F3 \\
\hline 1 & Weight Variation & 298 & 299 & 299 \\
\hline 2 & Hardness $\left(\mathrm{kg} / \mathrm{cm}^{2}\right)$ & 5.07 & 5.15 & 5.20 \\
\hline 3 & \% Friability $(\%)$ & 0.33 & 0.67 & 1.00 \\
\hline 4 & Thickness(mm) & 4 & 4 & 4 \\
\hline
\end{tabular}

\subsubsection{Determination of Drug Content:}

The results for drug content determination are predicted in Table 7.

Table 7: Determination of Drug Content

\begin{tabular}{|c|c|c|c|c|}
\hline $\begin{array}{c}\text { Formulation } \\
\text { code }\end{array}$ & $\begin{array}{c}\text { Polymer /drug } \\
\text { ratio }\end{array}$ & $\begin{array}{c}\text { Theoretical drug } \\
\text { content(mg) }\end{array}$ & $\begin{array}{c}\text { Actual drug } \\
\text { content (mg) }\end{array}$ & $\begin{array}{c}\text { Percentage } \\
\text { yield }\end{array}$ \\
\hline F1 & $1: 1$ & 80 & 71.80 & 89.55 \\
\hline F2 & $1: 2$ & 80 & 74.31 & 92.88 \\
\hline F3 & $1: 3$ & 80 & 77.04 & 96.3 \\
\hline
\end{tabular}




\subsubsection{In-vitro Drug Release Study of Sustained Release Propranolol HCl Bilayer Tablets:}

Data for in-vitro drug release study is shown in Table 8.

Table 8: Percentage Drug Release of Propranolol HCl Bilayer Tablet

\begin{tabular}{|c|c|c|c|}
\hline Time (hr) & F1 & F2 & F3 \\
\hline 1 & 18.54545 & 19.90909 & 20.72727 \\
\hline 2 & 20.31818 & 21.40909 & 25.09091 \\
\hline 3 & 22.22727 & 25.77273 & 30.40909 \\
\hline 4 & 27.13636 & 30.81818 & 33.95455 \\
\hline 5 & 31.77273 & 36.68182 & 38.45455 \\
\hline 6 & 36.13636 & 40.22727 & 45.13636 \\
\hline 7 & 40.5 & 46.22727 & 55.77273 \\
\hline 8 & 44.72727 & 50.18182 & 59.04545 \\
\hline 9 & 50.45455 & 58.09091 & 65.04545 \\
\hline 10 & 56.04545 & 63.68182 & 72.81818 \\
\hline 11 & 65.45455 & 70.5 & 80.04545 \\
\hline 12 & 69.54545 & 76.77273 & 87.40909 \\
\hline
\end{tabular}

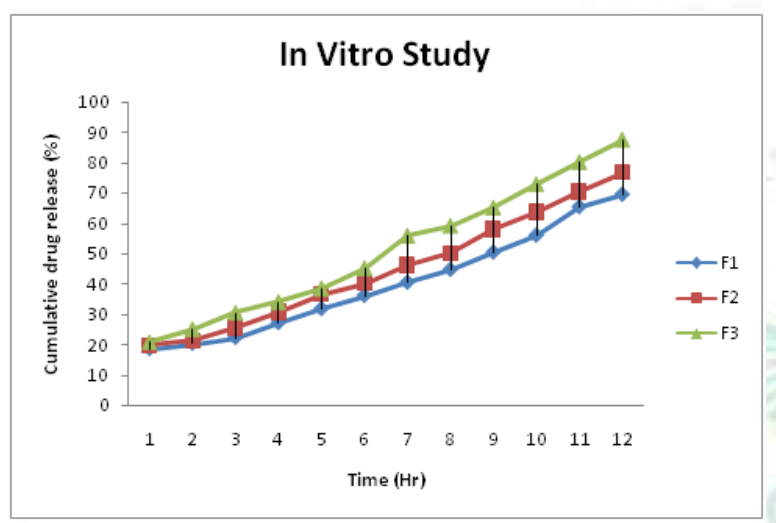

Figure 3: In vitro Drug Release Study of Propranolol HCl Bilayer Tablets

\section{CONCLUSION:}

In the present study, an attempt was made to prepare and evaluate bilayered matrix tablets by using synthetic Polymer. The Bi-layer tablets were prepared by wet granulation method. The research was undertaken with the aim to formulate and evaluate the bilayer tablets of Propranolol $\mathrm{HCl}$ using Ethylcellulose as polymers. The FTIR analysis ruled out the interaction between drug and polymers used in the preparation. From results obtained, it was concluded that the formulation of bilayer tablet of Propranolol $\mathrm{HCl}$ containing Ethylcellulose (F3) as polymer was taken as ideal or optimized formulation for $12 \mathrm{hrs}$ high release of drug i.e. $87.40 \%$, high drug content i.e. $96.3 \%$ and high hardness as it fulfils all the requirement of sustained release dosage form.

\section{Acknowledgements:}

Author is Thankful to Renuka raw pharma Mumbai for Supplying gift sample of Propranolol Hydrochloride, and also thankful to Nitin salunke, Supriya Shinde for helping in overall work.

\section{Conflicts of Interest:}

No conflicts of interest. Authors alone are responsible for the content and writing of the paper. 


\section{REFERENCES:}

1. Jain NK. Controlled and novel drug delivery. 1sted. New Delhi: CBS Publishers; 2002: 79-92.

2. Shivakumar HN, Nath BS, Desai BG. Effect of added HPMC and HEC on the release of cetostearyl alcohol embedded diclofenac sodium from tables for controlled release. The Eastern Pharmacist 2001: 117-9.

3. Hosseinali T, Seyed AM, Tina BG. Preparation of sustained release matrix tables of aspirin with ethylcellulose, eudragit RS100 and eudragit S100 and studying the release profile and their sensitivity to Tablets hardness. Iranian Journal of Pharm Research 2003: 201-06.

4. Kale VV, Kaslival RH, Avari JG. Effect of matrix geometry on drug release from guar gum matrix Tablets. Ind Drugs 2005; 42: 84-6.

5. Martindale: The Extrapharmacopoeia, 31st ed. London: The royal pharmaceutical society; 1996.

6. Wade A, Weller PJ. Handbook of pharmaceutical excipients. 2nd ed. London: The Pharmaceutical Press; 1994: 261-290.

7. Mark. G, A practical guide from candidate drug selection to commercial dosage form in pharmaceutical preformulation and formulation. Inter pharm/crc Florida; 2004: 121-245.

8. Subramanyam CVS, Thimmasetty J. Laboratory manual of physical pharmaceutics. Delhi; VallabhPrakashan: 2005:5671

9. Subramanyam CVS. Textbook of physical pharmaceutics. VallabhPrakashan: Delhi; 2005: 61-69.

10. Mote PB, Rawat PK, Singh SK, Zadbuke NS, Salunke AA, Rajendra VB, formulation and evaluation of sustained release matrix tablets of anti-asthmatic agent using various polymers, Journal of Drug Delivery \& Therapeutics; 2013; 3(2):88-92

11. Garg A, Gupta MM, Taste masking and formulation developement \&evaluation of mouth dissolving tablets of levocetrizine dihydrochloride, Journal of Drug Delivery \& Therapeutics; 2013; 3(3):123-130
12. Debajyoti Ray, Amresh K Prusty. Designing and invitro studies of gastric floating Tabletss of Tramadol hydrochloride, Int J Appl Pharm. 2010; 2(4):12-16.

13. M. M. Gupta, B.Srivastava. Enhancement of flow property of poorly flowable Aceclofenac drug powder by preparation of spherical crystals using change method and making drug powder suitable for direct compression, Int $\mathrm{J}$ Current Pharmaceutical Review And Research 2010; 1(1):12-23.

14. Agrawal R, Pharmaceutical processing- a review on wet granulation technology. IJPFR. 2011; (1):65-83

15. Available on online URL; www.wikipedia.com. On direct compression of Tablets.

16. M.A.Abraham and A.Shirwaikar, Formulation of multilayered sustained release Tabletss using insoluable matrix system, Indian J. Pharma. Sci. 1997; 59:312,315.

17. Vercammen JP, Dauwe D, Brioen P, Possibility of use of Eudragit RS as a sustained release matrix agent for the incorporation of water soluable active compounds at high percentages, STP Pharma. Sci. 1997; 7:491-497.

18. Yie WC. Novel drug delivery systems. 2nd ed. Madison Avenue (NY): Marcel Dekker, Inc.; 1992.

19. Asgar A, Sharma SN. Evaluation of oral sustained release formulation. The Eastern Pharmacist 1991: 69-74.

20. Haider SS, Monnujan N, Shahriyar SM. Sustained release preparation of metoclopramide hydrochloride based on fatty matrix. Indian drugs 2002; 39:73-9.

21. Tripathi KD. Essentials of medical pharmacology. 5thed. New Delhi: Jaypee brothers medical publication (p) Ltd; 2003.

22. Katzung GB. Basic and clinical pharmacology. 8thed. New York: Mcgraw Hill; 2001: 210-215.

23. Setter SM. a clinical review with a focus on dual therapy. Clin Therapeutics 2003; 25(12):2991-3025

24. Robinson JR, Lee VH. Controlled drug delivery: fundamentals and applications. 2nd ed.. New York, INC; Marcel Dekker: 1987: 211-220. 